\title{
An integrated approach of immunogenomics and bioinformatics to identify new Tumor Associated Antigens (TAA) for mammary cancer immunological prevention Federica Cavallo1 ${ }^{1}$, Annalisa Astolfi ${ }^{3}$, Manuela Iezzi ${ }^{4}$, Francesca Cordero ${ }^{1,2}$, Pier-Luigi Lollini ${ }^{3}$, Guido Forni ${ }^{1}$ and Raffaele Calogero*1
}

\author{
Address: ${ }^{1}$ Dept. of Clinical and Biological Sciences, University of Torino, Az. Ospedaliera S. Luigi, Regione Gonzole 10, I-10043 Orbassano Italy, \\ ${ }^{2}$ Dept. of Informatics, University of Torino, Via Pessinetto 12, I-10100 Torino, Italy, ${ }^{3}$ Dept. of Experimental Pathology, University of Bologna, Viale \\ Filopanti 22, I-40126 Bologna, Italy and ${ }^{4}$ Dept. of Oncology and Neurosciences, University of Chieti, Via Colle dell'Ara, I-66013 Chieti, Italy \\ Email: Federica Cavallo - federica.cavallo@unito.it; Annalisa Astolfi - astolfi@alma.unibo.it; Manuela Iezzi - miezzi@unich.it; \\ Francesca Cordero - fcordero@di.unito.it; Pier-Luigi Lollini - pierluigi@lollini.dsnet.it; Guido Forni - guido.forni@unito.it; \\ Raffaele Calogero* - raffaele.calogero@unito.it \\ * Corresponding author
}

from Italian Society of Bioinformatics (BITS): Annual Meeting 2005

Milan, Italy, 17-19 March 2005

Published: I December 2005

BMC Bioinformatics 2005, 6(Suppl 4):S7 doi:I0.I I86/I47|-2105-6-S4-S7

\begin{abstract}
Background: Neoplastic transformation is a multistep process in which distinct gene products of specific cell regulatory pathways are involved at each stage. Identification of overexpressed genes provides an unprecedented opportunity to address the immune system against antigens typical of defined stages of neoplastic transformation. HER-2/neu/ERBB2 (Her2) oncogene is a prototype of deregulated oncogenic protein kinase membrane receptors. Mice transgenic for rat Her2 (BALBneuT mice) were studied to evaluate the stage in which vaccines can prevent the onset of Her2 driven mammary carcinomas. As Her2 is not overexpressed in all mammary carcinomas, definition of an additional set of tumor associated antigens (TAAs) expressed at defined stages by most breast carcinomas would allow a broader coverage of vaccination. To address this question, a metaanalysis was performed on two transcription profile studies $[1,2]$ to identify a set of new TAA targets to be used instead of or in conjunction with Her2.

Results: The five TAAs identified (Tes, Rcn2, Rnf4, Cradd, Galnt3) are those whose expression is linearly related to the tumor mass increase in BALB-neuT mammary glands. Moreover, they have a low expression in normal tissues and are generally expressed in human breast tumors, though at a lower level than Her2.

Conclusion: Although the number of putative TAAs identified is limited, this pilot study suggests that meta-analysis of expression profiles produces results that could assist in the designing of preclinical immunopreventive vaccines.
\end{abstract}

\section{Background}

One of the most significant tenet of tumor immunology is the assumption that the immune system is able to discriminate between normal and neoplastic tissues. As this distinction is based on the overexpression of TAAs, the discovery of TAAs and their molecular and genetic characterization is important in both tumor immunodiagnosis and immunotherapy. 
The progressive elucidation of the nature of TAAs recognized by antibodies and $\mathrm{T}$ lymphocytes coupled with the elaboration of methods for their isolation and synthesis of their peptides is leading towards new formulations of antitumor vaccines. Despite of the fact that long lists of well-characterized TAAs recognized by T cells [3] and by antibodies [4] are currently available, the attempts to use them to arouse an immune response able to cure tumor patients has met with very little success, at least so far [5]. Towards this goal significant obstacles are posed by the patient's state of immunosuppression and the numerous mechanisms to evade the immune response that a tumor progressively acquires [6]. This two order of obstacles might suggest that active immunotherapy is not very appropriate for patients with advanced tumors.

A more modern endeavor is to exploit the potential of the immune response elicited by a vaccine against more plausible targets, such as pre-neoplastic lesions. In this case, the immune response may be addressed towards TAAs that are already present in early lesions and that remain overexpressed during the progression of the tumor [7]. Identification of TAAs on preneoplastic cells will provide the opportunity to trigger the immune system against transformed cells at their earliest manifestation [8]. The availability of animal models of autochthonous carcinogenesis offers an unprecedented opportunity to identify this kind of TAAs and to test the efficacy of the immune control of preneoplastic lesions [9]. A preneoplastic lesion formed by few cells characterized by an indolent proliferation both displays a limited genetic instability and is more permeable to an immune attack than a large tumor $[10,11]$. In addition it is possible that early expressed TAAs are more suitable target for tumor immune prevention than most of the already defined TAAs.

The characterization of TAAs expressed in early lesions is a prerequisite for setting up protocols for tumor prevention instead of for tumor cure [12]. The protein product of the oncogene Her2 [13], IGF-R [14] and cyclin B1 [15] are significant examples of early expressed TAAs causally involved in the progression of the lesions [7].

Mouse strains transgenic for oncogenes or knock-out for oncosuppressor genes that consequently develop defined kind of tumors are being used for preclinical assessment of the potential of preventive vaccines $[16,11]$.

By combining the information provided by the genome sequence and the expression profiles of entire transcriptomes (microarrays), these mouse models can also lead towards the identification of TAAs expressed during progressive stages of carcinogenesis. Microarrays are an attractive way of identifying new TAAs since their procedure is now firmly established [17] and they are well suited to the intrinsic limitations of the biological material to be examined (e.g. the small amount of starting material). This paper describes our application of meta-analysis to two BALB-neuT mice transcription profiling studies $[1,2]$ to evaluate the possibility of identifying, within the tumor modulated genes, a set of new putative targets to be used as TAAs instead of or in conjunction with Her2.

\section{Results and discussion}

Our previous demonstration of persistent inhibition of autochthonous preneoplastic lesions in a mouse model of Her2 mammary carcinogenesis by a combined DNA and cell vaccine [1], and the curing of Her2 transplantable tumors by DNA vaccination [18] indicates that efficient immunological inhibition of Her2 carcinogenesis can be achieved. We have also shown that two transcriptional profiling studies based on different immunization protocols in BALB-neuT mice [1,2] are integrable [17]. Since an important issue of DNA vaccination is the definition of a set of target genes other that Her2 in order to broaden its effective coverage, we decided to use these data to identify a set of new TAAs to be used in DNA vaccination.

\section{Datasets}

Seven prototypic situations were evaluated. Mammary glands from: (a) 6-week-old mice (wk6nt), displaying atypical hyperplasia; (b) 10-week-old mice (wk10nt), showing atypical hyperplasia and some foci of in situ carcinomas; (c) 15-week-old mice (wk15nt), with diffuse hyperplasia and in situ carcinomas; (d) 19-week-old mice (wk19nt), displaying lobular invasive carcinomas; (e) 22week-old mice (wk22nt), with palpable carcinomas; (f) 26-week-old mice (wk26nt), with large lobular and metastasizing carcinomas, (g) 2-week-pregnant (wk2prg) wild type $\mathrm{BALB} / \mathrm{c}$ mice displaying marked pregnancyrelated hyperplasia $[19,1]$. wk6nt, wk15nt, wk19nt and wk26nt gland expression profiles were derived from Astolfi [2], wk10nt, wk22nt and wk2prg gland profiles from Quaglino [1].

\section{Selection of genes whose expression is linearly correlated with the increase of the tumor}

The number of neoplastic cells in the mammary tissue of BALB-neuT mice increases constantly during aging, and at 19-22 weeks a tumor mass becomes palpable in all their mammary glands. Previously [17] we have used PCA (Principal Component Analysis) to show that the transcriptional profiles of BALB-neuT mammary glands are linearly correlated with age (i.e. in function of the increment of tumor cellularity in the mammary glands, fig. 1). We identified 205 probe sets by linear fitting each gene expression with respect to age (fig. 2). Only one probe set was linked to an unmapped EST http://www.bioinformat ica.unito.it/bioinformatics/Forni3/, whereas the others were linked to annotated mouse genes. Investigation of 
A
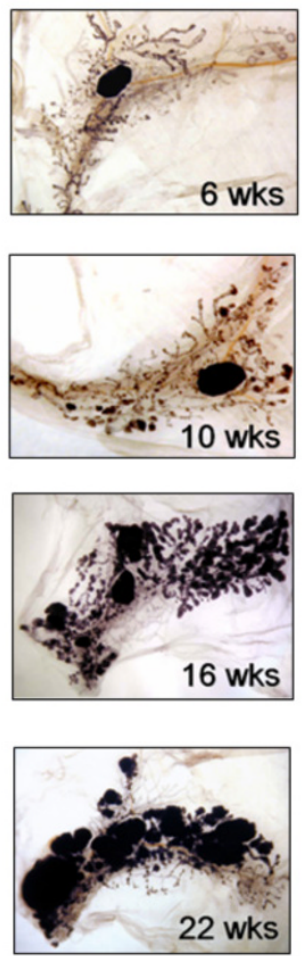

B

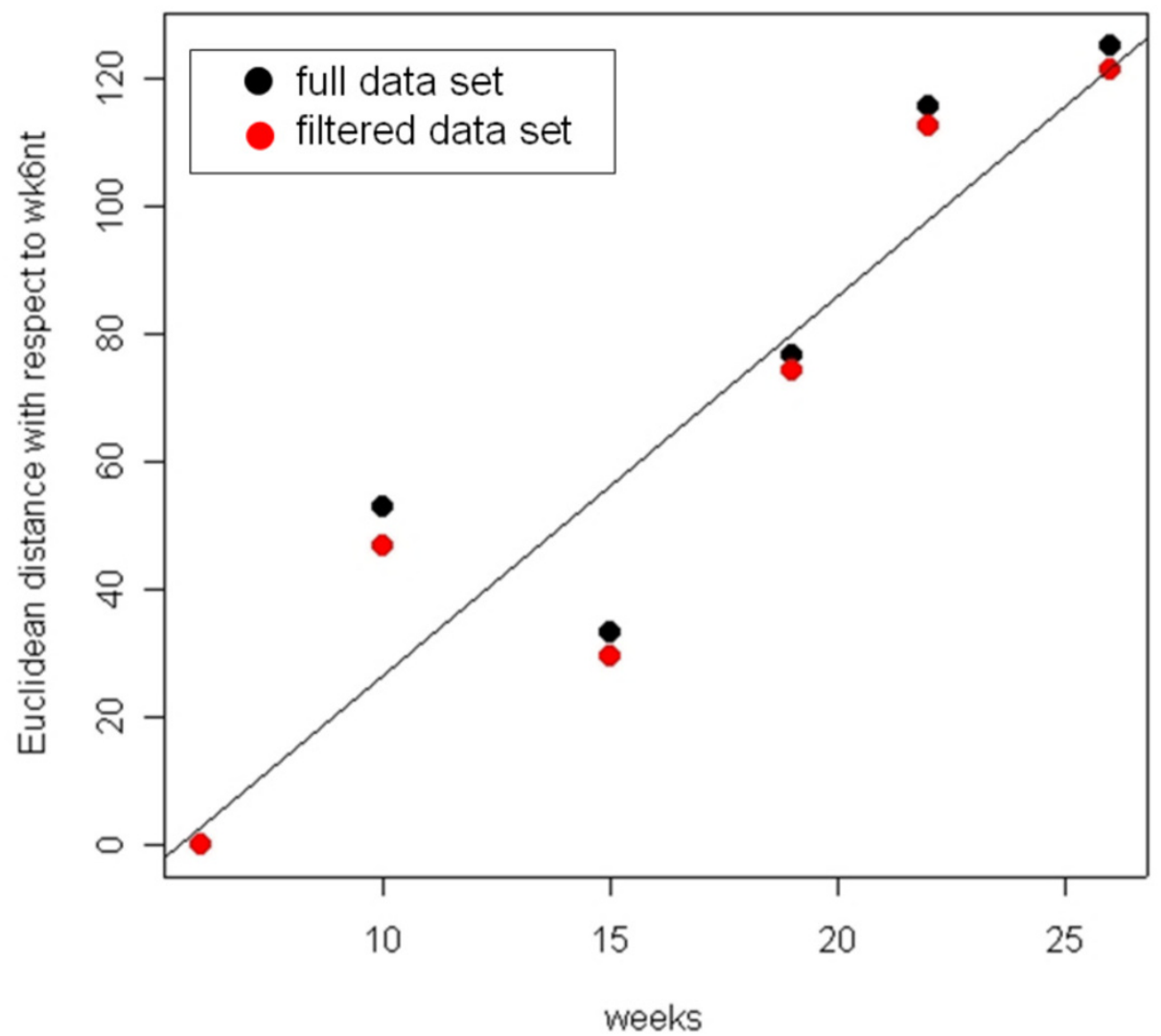

Figure I

BALB-neuT mammary gland morphology and transcription profile similarities. A) Morphological preparation called "whole mount", that allows the observation of the entire mammary gland. The draining lymph node, vessels, ducts and ductules are evident. Clearly the amount of tumor mass increases from 6 to 22 weeks. 19 weeks picture was omitted since it is very similar to 22 weeks. At 26 weeks the tumor mass is palpable in all the mammary glands, and the "whole mount" picture is very similar to 22 weeks old mice (not shown). B) Euclidean distance of the expression profiles derived by mammary glands from 6 to 26 weeks old BALB-neuT mice measured with respect to 6 weeks old mice. Black dots refer to the average distance generated using all microarray data. Red dots refer to the average distance calculated using only microarray data showing an IQR greater than 0.5 .

specific gene ontology (GO) class (BP, biological process; $\mathrm{MF}$, molecular function; CC, cellular component) overrepresentation within the annotated 204 genes revealed significant enrichments in functions associated with the extracellular compartment (table 1). Pathway analysis showed the presence of 6 genes involved in the integrin signal transduction pathway (fig. 3) linked to Her2 action $[20,21]$.

\section{Evaluation of the expression of tumor-related genes in} normal mouse tissues

If a TAA is to be used as a vaccination target, its expression must be low in normal tissues. To evaluate the expression of the 204 putative TAAs in normal tissues, we used transcription profiles recently published by $\mathrm{Su}$ [22]. The mouse atlas (GNFm) was generated by using a custom Affymetrix array which interrogates 17,108 annotated mouse genes: 171 of the putative TAAs are present in 


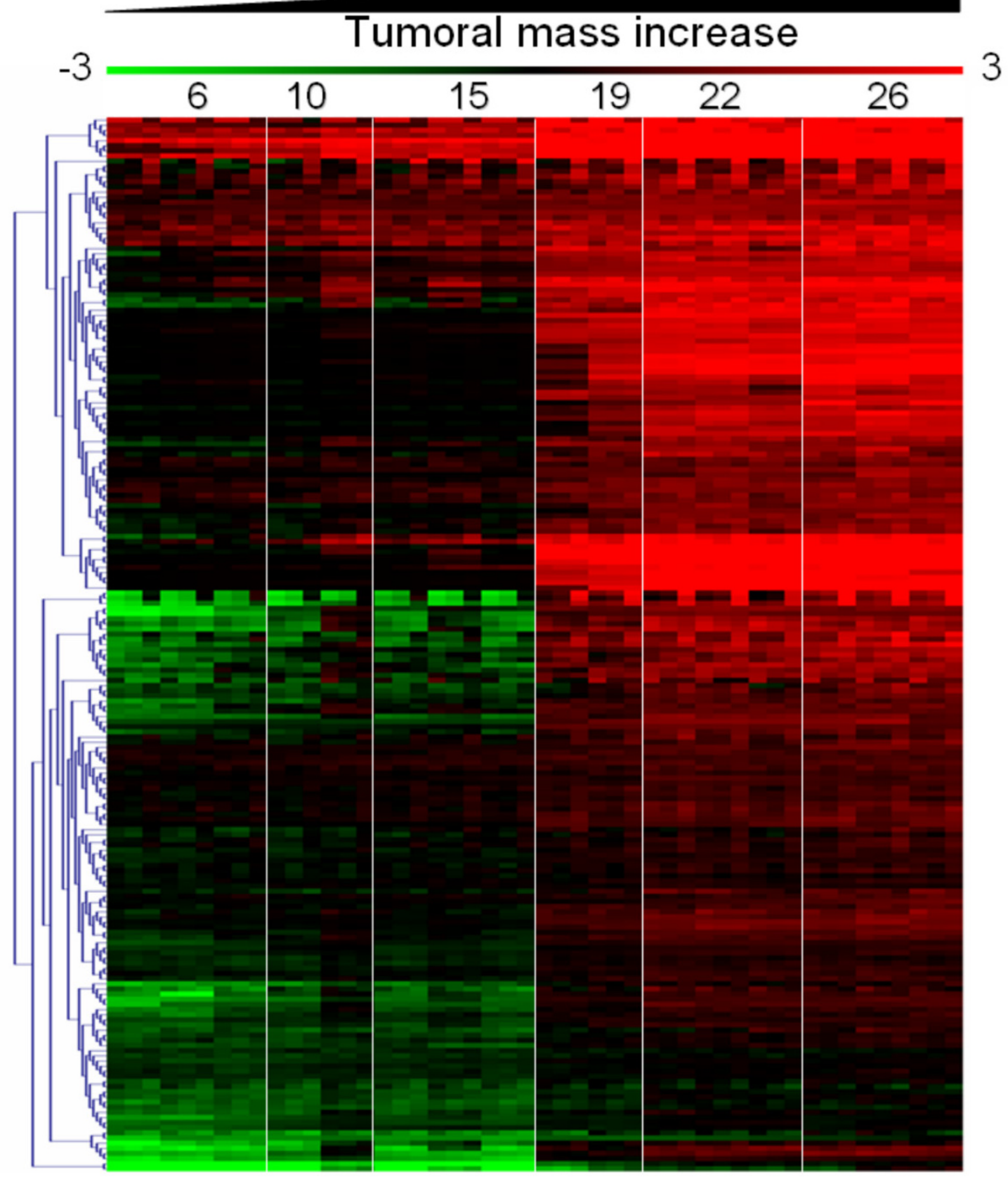

Figure 2

Transcription profiles as virtual two dye experiments. Each of the experimental points are represented as ratio with respect to wk2prg mice displaying marked pregnancy-related hyperplasia. The expression level of the genes associated to tumor cells increases with the animal age since tumor cells are replacing the conventional cellular environment of a normal mammary gland. 
GNFm, twelve of them (table 2) characterized by low expression (see material and methods) in normal mouse tissues.

\section{Expression of tumor related genes in normal and cancer human tissues}

The 12 genes identified as TAAs were expressed in all the stages of breast carcinogenesis in BALB-neuT mice and characterized by low expression in normal mouse tissues. To determine whether these characteristics were also present in the corresponding human genes, we cross-validated the expression of the 12 TAAs within the human tissue expression atlas published by Yanai [23]. Since Her2 is expressed at very low levels in normal human tissues, we used it as the "ideal reference" of low expression. Rtn1, Irf6, Sel1L were discarded since their expression levels in some human tissues were higher than those of Her2 (data not shown). Tes, Rcn2, Rnf4, Cradd, Galnt3, Clca1, Cdcp1, Socs2 and Spred2 were expressed at levels similar to Her2.

We also assessed the expression of these 9 TAAs in human breast specimens. Of the breast cancer transcriptional profiling data sets available [24-26], that proposed by van't Veer [26] is ideal because its experimental structure allows evaluation of the expression level distribution within the specimens. Fold change variation of each specimen is measured with respect to a reference pool composed by mixing the same amount of all RNA of the sporadic patients [26].

The 9 TAAs and Her2 were represented in the van't Veer set [26], Her2 was highly expressed, while Tes, Rcn2, Rnf4, Cradd and Galnt 3 were medium expressed. Clca1, Cdcp1, Socs 2 and Spred2 were low expressed group (fig. 4) and since their expression was 100 times lower than that of Her2 they were discarded as putative vaccination targets. Even though Tes, Rcn2, Rnf4, Cradd and Galnt3 were less expressed than Her2, they were less scattered than Her2 (fig. 4). The highest expressed is Tes, which maps to a fragile site on chromosome 7q31.2 [27] and may have a tumor suppression activity [28]. It is homogeneously expressed in all the 78 cancer specimens in the van't Veer set [26]. The function of Rcn2, reticulocalbin, has not been characterized. It is implicated in tumor cell invasiveness, as it is expressed in the highly invasive breast cancer cell lines, but not in poorly invasive ones [29]. Rnf4 is a RING-finger protein which acts as a transcription regulator [30], it is not only a coactivator in steroid receptordependent transcription but also activates transcription from steroid-independent promoters [31]. It is expressed at very high levels in testis and at much lower levels in several other tissues. When ectopically expressed, it inhibits the proliferation of both somatic and germ cell tumorderived cells [32,33]. Cradd encodes a death domain
(CARD/DD)-containing protein and induces apoptosis [34,35]. Galnt3 encodes UDP-GalNAc transferase 3, a member of the GalNAc-transferases family. In gallbladder cancer, the presence of diffuse-type localization of Gal$\mathrm{NAc-T3}$ in the subserosal layer is correlated with aggressiveness [36]. Furthermore, Galnt3 expression is associated with the differentiation and aggressiveness of ductal adenocarcinoma of the pancreas [37].

\section{Conclusion}

This study identified 12 putative TAAs. Three were discarded because they were expressed in some normal human tissues and four because their expression was too low in human cancer specimens. Tes, Rcn2, Rnf4, Cradd and Galnt3 were retained for further studies. This work was based on in silico analysis of published transcriptional profiling studies. Its results must now be referred back to the in vivo pre-clinical experimentation.

We shall select the most immunogenic domains of the 5 candidate TAAs and use them in vaccination protocols in BALB-neuT mice $[9,38]$. Other interesting TAAs may have been missed in this analysis since it integrates two independent experiments and this increases the experimental noise. A further limitation could be the partial coverage of the mouse transcriptome of the arrays employed. A new transcription profiling study covering the same experimental points, but using full genome-wide mouse arrays is now in progress.

\section{Methods}

\section{Microarray data}

The .CEL files from Quaglino [1], Astolfi [2], Su [22] were kindly provided by the authors. The van't Veer data set [26] was obtained from the Rosetta Inpharmatics web site http://www.rii.com/publications/2002/default.html.

\section{Data analysis}

Microarray data analysis was performed using Bioconductor libraries [39]. Probe set intensities were calculated using the gcRMA algorithm http://www.bepress.com/cgi/ viewcontent.cgi? article $=1001 \&$ context $=$ jhubiostat and normalized by the quantiles method [40]. The full data set (wk6nt 4 arrays, wk10nt 2 arrays, wk15t 3 arrays, wk19nt 2 arrays, wk22nt 3 arrays, wk26nt 3 arrays) was filtered to select probe sets with an intra-experiment Inter Quantile Range (IQR) greater than 0.5 . We used a statistical linear model to measure the effects of time on gene expression and to identify probe sets linearly correlated to the increment of the tumor mass. In equation (1) $\mathrm{y}_{\mathrm{ij}}$ is the observed expression level for probe set $\mathrm{i}$ in sample $\mathrm{j}(\mathrm{j}=1, \ldots, 16) . \mu$ is the average expression level of probe set $\mathrm{i}$ and $\beta_{\text {time }}$ represents the effect of time on the expression level of probe set $i, \varepsilon$ represents random error for probe set $\mathrm{i}$ and sample $\mathrm{j}$, and is assumed to be independent for each probe set and 
Table I: GO classes found enriched by mean of hypergeometric distribution within the 204 genes linearly linked to tumor mass increase.

\begin{tabular}{|c|c|c|c|c|c|}
\hline GO class & Description & p value & $\begin{array}{l}\text { N. of found items } \\
\text { within the } 204 \\
\text { differentially } \\
\text { expressed genes }\end{array}$ & $\begin{array}{l}\text { N. of items } \\
\text { belonging to the } \\
\text { GO class within the } \\
\text { mgu74av2 chip. }\end{array}$ & GO \\
\hline GO:0007I55 & Cell adhesion & 0.000 & 19 & 250 & $\mathrm{BP}$ \\
\hline GO:0030198 & $\begin{array}{l}\text { Extracellular matrix } \\
\text { organization and } \\
\text { biogenesis }\end{array}$ & 0.005 & 3 & 17 & $\mathrm{BP}$ \\
\hline GO:0007160 & Cell-matrix adhesion & 0.005 & 4 & 34 & $\mathrm{BP}$ \\
\hline GO:000520I & $\begin{array}{l}\text { Extracellular matrix } \\
\text { structural constituent }\end{array}$ & 0.003 & 5 & 47 & MF \\
\hline GO:000820I & Heparin binding & 0.004 & 4 & 39 & MF \\
\hline GO:0005576 & Extracellular & 0.000 & 58 & 1631 & $\mathrm{CC}$ \\
\hline GO:00056I5 & Extracellular space & 0.000 & 54 & 1514 & $\mathrm{CC}$ \\
\hline GO:0005794 & Golgi apparatus & 0.004 & 12 & 209 & $\mathrm{CC}$ \\
\hline GO:000558I & collagen & 0.004 & 4 & 28 & $\mathrm{CC}$ \\
\hline GO:0016327 & $\begin{array}{c}\text { Apicolateral plasma } \\
\text { membrane }\end{array}$ & 0.004 & 6 & 65 & $\mathrm{CC}$ \\
\hline GO:0016020 & Membrane & 0.005 & 69 & 22285 & $\mathrm{CC}$ \\
\hline GO:0030054 & Cell junction & 0.006 & 6 & 71 & $\mathrm{CC}$ \\
\hline GO:0005923 & Tight junction & 0.007 & 3 & 17 & $\mathrm{CC}$ \\
\hline GO:00059II & Intercellular junction & 0.007 & 5 & 52 & $\mathrm{CC}$ \\
\hline GO:0030057 & Desmosome & 0.008 & 2 & 6 & $\mathrm{CC}$ \\
\hline GO:0005578 & Extracellular matrix & 0.008 & 11 & 204 & $\mathrm{CC}$ \\
\hline
\end{tabular}
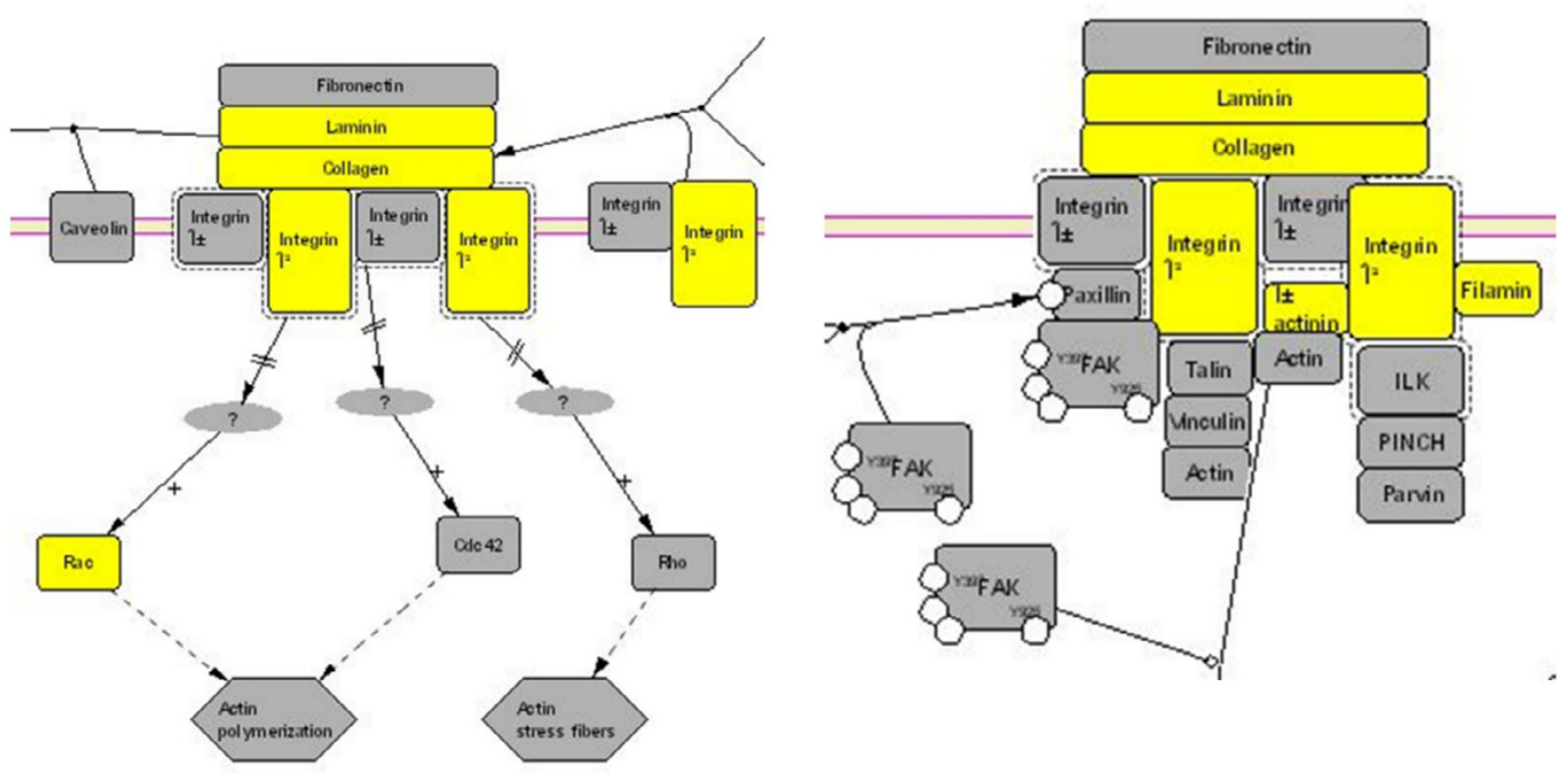

Figure 3

Integrin signal transduction pathway. Part of the integrin signal transduction pathway characterized by an over-representation of 6/204 genes showing an expression linearly linked to the tumor mass increment. The 6 genes found overrepresented are colored in yellow in the integrin pathway. 
Table 2: Genes, having expression linked to tumor mass increase, showing low expression levels in the GNFm tissue atlas. 12 genes were showing a limited expression at transcriptional level in the normal murine tissue expression atlas.

\begin{tabular}{|c|c|c|c|c|c|}
\hline Symbol & GNFm ID & Mm Affy IDs & Mm Gene IDs & Hs Gene IDs & $\begin{array}{c}\text { Expression similar } \\
\text { to Her } 2 \text { in human } \\
\text { tissues }\end{array}$ \\
\hline Socs 2 & gnflm24576_at & 99475_at & 216233 & 8835 & $Y$ \\
\hline Spred2 & gnflm09332_s_at & 161070_at & 114716 & 200734 & $Y$ \\
\hline Cdcpl & gnflmI2020_a_at & 104198_at & 109332 & 64866 & Y \\
\hline Rtnl & gnflm I5854_at & 94545_at & 104001 & 6252 & $\mathrm{~N}$ \\
\hline Irf6 & gnflm I308I_at & 92440_at & 54139 & 3664 & $N$ \\
\hline $\operatorname{Ren} 2$ & gnflm24916_at & 9328I_at & 26611 & 5955 & $Y$ \\
\hline Tes & gnflm02859_at & 101551_s_at & 21753 & 26136 & $Y$ \\
\hline SelIL & gnflm30768_a_at & 92870_at, 9287I_at & 20338 & 6400 & $\mathrm{~N}$ \\
\hline Rnf4 & gnf Im25286_at & 93782_at & 19822 & 6047 & $Y$ \\
\hline Galnt3 & gnflm24047_at & 9901I_at & 14425 & 2591 & $Y$ \\
\hline Cradd & gnflm2766I_at & 102952_g_at & 12905 & 8738 & $Y$ \\
\hline Clcal & gnflm|3262_a_at & 103812_at & 12722 & 1179 & $Y$ \\
\hline
\end{tabular}

sample, and normally distributed with mean 0 and variance $\sigma^{2}$.

$\mathrm{y}_{i j}=\mu_{i}+\beta_{\text {time }}+\varepsilon_{i j}$

205 probe sets were identified as putative TAAs by selecting only the expression profiles characterized by an $\mathrm{r}^{2}>$ 0.7 , and a positive slope $(\mathrm{p}<0.001)$ of the linear fitting of expression versus the animal age.

Virtual two-dye experiments were done as previously published [1] using as reference wk2prg (3 arrays).

GO class enrichment was evaluated with the Bioconductor GOstats package and the annotation library mgu74av2 1.6.8. Pathway analysis was performed with the PANTHER annotation tool https://panther.appliedbiosys tems.com/.

Expression level of the probe sets within mouse tissues was evaluated using the mouse tissue expression atlas (GNFm) published by Su [22]. 171 of the 204 putative TAAs were mapped within GNFm. The expression of 12 of them was located in the low expression tail of the GNFm distribution ( $\mid \log _{2}$ (average intensity) $\mid<7$ ) and narrowly distributed within the GNFm tissues (IQR of the inter-tissue expression $<0.5)$. The expression of 12 TAAs was compared to that of Her2 in the human normal tissue expression atlas published by Yanai [23] by using their web interface http://genecards.weizmann.ac.il/cgi-bin/ genenote/home page.pl.

The expression of 9 TAAs was evaluated within the breast cancer transcription profiling study produced by van't Veer [26]. Since in this experiment the gene identifiers are
EST accession numbers, the Entrez Gene identifier [41] associated with each putative TAA was searched in the

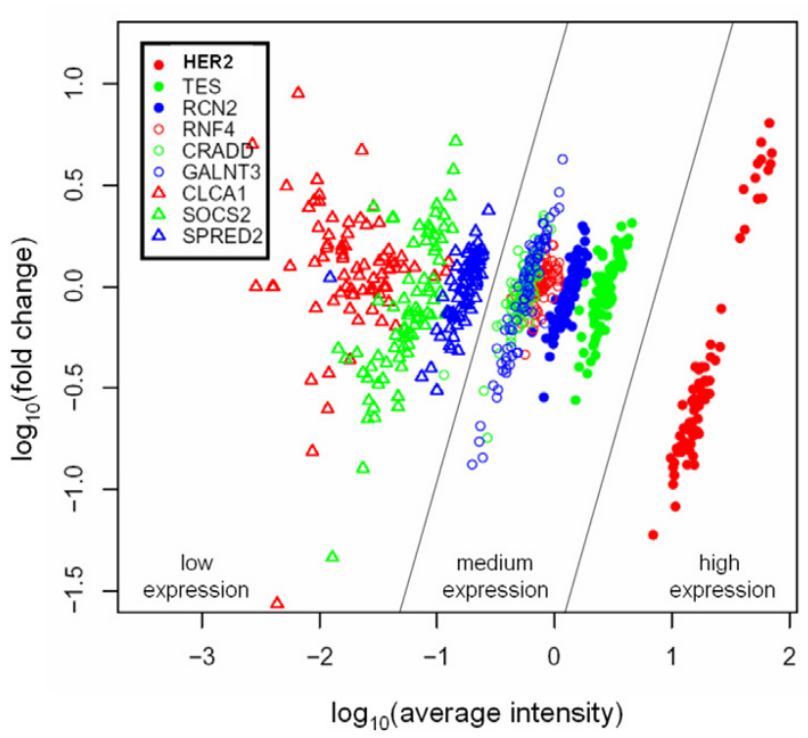

Figure 4

Fold change variation versus average intensities of putative TAAs in van't Veer data set. Log $_{10}$ fold change variation with respect to a reference pool (the reference pool is made of the same amount of all sporadic patients [26]) is plotted in function of $\log _{10}$ average intensities [42]. The 9 putative TAAs are grouped with respect to Her2 expression as medium expressed and low expressed. Genes belonging to the medium expressed group have a median average expression level between I/10 to I/I00 of median Her2 expression. Genes belonging to the low expressed group have a median average expression level lower than I/ 100 of median Her2 expression. 
homologene database http://www.ncbi.nlm.nih.gov/ent rez/query.fcgi? $\mathrm{db}=$ homologene and the corresponding orthologous human Entrez Gene identifier (HsEG) was selected. A Perl http://www.perl.org script was used to link HsEG to all the accession numbers of EST associated with them in the UniGene database (downloaded from http:// ftp.ncbi.nih.gov on 3/3/2005). The ESTs accession numbers were then searched in the van't Veer data set [26], together with the Her2 gene. In this experiment, RNA expression for each of the 78 breast cancer tumors is evaluated as the $\log _{10}$ differential expression with respect to a pool composed by mixing the same amount of all RNA of the sporadic patients [26].

\section{Authors' contributions}

$\mathrm{CaF}$ and $\mathrm{AA}$ carried out the microarray experiments and drafted the manuscript. MI performed whole mount analysis of BALB-neuT mammary glands. CoF participated in the microarray data analysis. CaF, LPL and FG participated in the design of the study and performed literature analysis. CR conceived the study, participated in its design and coordination and helped to draft the manuscript. All authors read and approved the final manuscript.

\section{Additional material}

\section{Additional File 1}

Annotation of the 204 genes showing an expression linearly related to the tumor mass increase. $e$ annotation of the 204 genes showing a linear correlation with the increase of the tumor mass in the BALB-neuT murine cancer model was carried out using the mgu74v2 1.6.8 and the annaffy Bioconductor libraries.

Click here for file

[http://www.biomedcentral.com/content/supplementary/14712105-6-S4-S7-S1.html]

\section{Acknowledgements}

This work was supported by grants from: the Italian Association for Cancer Research (AIRC); the Italian Ministry for Education, the Universities and Research (MIUR), FIRB projects RBAU0I2RLC, RBNE0I7B4C, RBAU0 IJTHS, RBNE0 I57EH; the Italian Ministry of Health; the University of Turin. We thank Prof. John lliffe for his critical review of the manuscript and for helpful discussions.

\section{References}

I. Quaglino E, Rolla S, lezzi M, Spadaro M, Musiani P, De Giovanni C, Lollini PL, Lanzardo S, Forni G, Sanges R, Crispi S, De Luca P, Calogero $\mathrm{R}$, Cavallo F: Concordant morphologic and gene expression data show that a vaccine halts HER-2/neu preneoplastic lesions. J Clin Invest 2004, I 13:709-717.

2. Astolfi A, Landuzzi L, Nicoletti G, De Giovanni C, Croci S, Palladini A, Ferrini S, lezzi M, Musiani P, Cavallo F, Forni G, Nanni P, Lollini PL: Gene Expression Analysis of Immune-Mediated Arrest of Tumorigenesis in a Transgenic Mouse Model of HER-2/neuPositive Basal-Like Mammary Carcinoma. Am J Pathol 2005, 166:1205-16.

3. Van Der Bruggen $P$, Zhang $Y$, Chaux $P$, Stroobant $V$, Panichelli $C$, Schultz ES, Chapiro J, Van Den Eynde BJ, Brasseur F, Boon T: Tumor- specific shared antigenic peptides recognized by human $\mathbf{T}$ cells. Immunol Rev 2002, I 88:5I-64.

4. Scanlan MJ, Gout I, Gordon CM, Williamson B, Stockert E, Gure AO, Jager D, Chen YT, Mackay A, O'Hare MJ, Old LJ: Humoral immunity to human breast cancer: antigen definition and quantitative analysis of mRNA expression. Cancer Immun 200I, I:4.

5. Rosenberg SA, Yang HC, Restifo NP: Moving beyond current vaccines. Nat Med 2004, 10:909-915.

6. Marincola FM, Jaffee EM, Hicklin DJ, Ferrone S: Escape of human solid tumors from $T$-cell recognition: molecular mechanisms and functional significance. Adv Immunol 2000, 74: I8I-273.

7. Lollini PL, Forni G: Antitumor vaccines: is it possible to prevent a tumor? Cancer Immunol Immunother 2002, 5 I:409-4I6.

8. Finn OJ: Premalignant lesions as targets for cancer vaccines. J Exp Med 2003, I 98: I623-I626.

9. Quaglino E, lezzi M, Mastini C, Amici A, Pericle F, Di Carlo E, Pupa SM, De Giovanni C, Spadaro M, Curcio C, Lollini PL, Musiani P, Forni G, Cavallo F: Electroporated DNA vaccine clears away multifocal mammary carcinomas in her-2/neu transgenic mice. Cancer Res 2004, 64:2858-2864.

10. Thomasset N, Lochter A, Sympson CJ, Lund LR, Williams DR, Behrendtsen O, Werb Z, Bissell MJ: Expression of autoactivated stromelysin-I in mammary glands of transgenic mice leads to a reactive stroma during early development. Am J Pathol 1998, I 53:457-467.

II. Forni G, Lollini PL, Musiani P, Colombo MP: Immunoprevention of cancer: is the time ripe? Cancer Res 2000, 60:2571-2575.

12. Finn OJ: Cancer vaccines: between the idea and the reality. Nat Rev Immunol 2003, 3:630-64l.

13. Xu R, Perle MA, Inghirami G, Chan W, Delgado Y, Feiner H: Amplification of Her-2/neu gene in Her-2/neu-overexpressing and -nonexpressing breast carcinomas and their synchronous benign, premalignant, and metastatic lesions detected by FISH in archival material. Mod Pathol 2002, I 5: I 16-124.

14. Byron SA, Yee D: Potential therapeutic strategies to interrupt insulin-like growth factor signaling in breast cancer. Semin Oncol 2003, I6s: | 25.

I5. Kao H, Marto JA, Hoffmann TK, Shabanowitz J, Finkelstein SD, Whiteside TL, Hunt DF, Finn OJ: Identification of cyclin B I as a shared human epithelial tumor-associated antigen recognized by $T$ cells. J Exp Med 2001, 194:1313-1323.

16. Ostrand-Rosenberg S: Animal models of tumor immunity, immunotherapy and cancer vaccines. Curr Opin Immunol 2004, 16:143-150.

17. Astolfi A, Rolla S, Nanni P, Quaglino E, De Giovanni C, lezzi M, Musiani P, Forni G, Lollini PL, Cavallo F, Calogero RA: Immune prevention of mammary carcinogenesis in HER-2/neu transgenic mice: a microarray scenario. Cancer Immunol Immunother 2005, 54:599-6I0.

18. Curcio C, Di Carlo E, Clynes R, Smyth MJ, Boggio K, Quaglino E, Spadaro M, Colombo MP, Amici A, Lollini PL, Musiani P, Forni G: Nonredundant roles of antibody, cytokines, and perforin in the eradication of established Her-2/neu carcinomas. J Clin Invest 2003, I I I: I |6I-II70.

19. Di Carlo E, Diodoro MG, Boggio K, Modesti A, Modesti M, Nanni P, Forni G, Musiani P: Analysis of mammary carcinoma onset and progression in HER-2/neu oncogene transgenic mice reveals a lobular origin. Lab Invest 1999, 79:1261-1269.

20. Lindberg LE, Hedjazifar S, Baeckstrom D: c-erbB2-induced disruption of matrix adhesion and morphogenesis reveals a novel role for protein kinase $B$ as a negative regulator of alpha(2)beta(I) integrin function. Mol Biol Cell 2002, 3:2894-2908

21. Shimizu H, Koyama N, Asada M, Yoshimatsu K: Aberrant expression of integrin and erbB subunits in breast cancer cell lines. Int J Oncol 2002, 2 I: 1073-1079.

22. Su Al, Wiltshire T, Batalov S, Lapp H, Ching KA, Block D, Zhang J Soden R, Hayakawa M, Kreiman G, Cooke MP, Walker JR, Hogenesch JB: $A$ gene atlas of the mouse and human protein-encoding transcriptomes. Proc Natl Acad Sci U S A 2004, I 0 I:6062-6067.

23. Yanai I, Benjamin H, Shmoish M, Chalifa-Caspi V, Shklar M, Ophir R, Bar-Even A, Horn-Saban S, Safran M, Domany E, Lancet D, Shmueli O: Genome-wide midrange transcription profiles reveal expression level relationships in human tissue specification. Bioinformatics 2005, 21:650-659. 
24. Sotiriou C, Neo SY, McShane LM, Korn EL, Long PM, Jazaeri A, Martiat $P$, Fox SB, Harris AL, Liu ET: Breast cancer classification and prognosis based on gene expression profiles from a population-based study. Proc Natl Acad Sci U S A 2003, 100:10393-10398.

25. Perou CM, Sorlie T, Eisen MB, van de Rijn M, Jeffrey SS, Rees CA, Pollack JR, Ross DT, Johnsen H, Akslen LA, Fluge O, Pergamenschikov $A$ Williams C, Zhu SX, Lonning PE, Borresen-Dale AL, Brown PO, Botstein D: Molecular portraits of human breast tumours. Nature 2000, 406:747-752.

26. van 't Veer LJ, Dai $H$, van de Vijver MJ, He YD, Hart AA, Mao M, Peterse HL, van der Kooy K, Marton MJ, Witteveen AT, Schreiber G], Kerkhoven RM, Roberts C, Linsley PS, Bernards R, Friend SH: Gene expression profiling predicts clinical outcome of breast cancer. Nature 2002, 415:530-536.

27. Han SY, Druck T, Huebner K: Candidate tumor suppressor genes at FRA7G are coamplified with MET and do not suppress malignancy in a gastric cancer. Genomics 2003, 8I:105-107.

28. Sarti M, Sevignani C, Calin GA, Aqeilan R, Shimizu M, Pentimalli F, Picchio MC, Godwin A, Rosenberg A, Drusco A, Negrini M, Croce CM: Adenoviral transduction of TESTIN gene into breast and uterine cancer cell lines promotes apoptosis and tumor reduction in vivo. Clin Cancer Res 2005, I I:806-I3.

29. Liu Z, Brattain MG, Appert H: Differential display of reticulocalbin in the highly invasive cell line, MDA-MB-435, versus the poorly invasive cell line, MCF-7. Biochem Biophys Res Commun 1997, 23 I:283-9.

30. Kaiser F], Moroy T, Chang GT, Horsthemke B, Ludecke HJ: The RING finger protein RNF4, a co-regulator of transcription, interacts with the TRPSI transcription factor. J Biol Chem 2003, 278:38780-38785

31. Poukka H, Aarnisalo P, Santti H, Janne OA, Palvimo Jj: Coregulator small nuclear RING finger protein (SNURF) enhances SpIand steroid receptor-mediated transcription by different mechanisms. J Biol Chem 2000, 275:57I-579.

32. Pero R, Lembo F, Di Vizio D, Boccia A, Chieffi P, Fedele M, Pierantoni GM, Rossi P, Iuliano R, Santoro M, Viglietto G, Bruni CB, Fusco A, Chiariotti L: RNF4 is a growth inhibitor expressed in germ cells but not in human testicular tumors. Am J Pathol 200I, I 59: $1225-1230$

33. Hirvonen-Santti SJ, Sriraman V, Anttonen M, Savolainen S, Palvimo JJ, Heikinheimo M, Richards JS, Janne OA: Small nuclear RING finger protein expression during gonad development: regulation by gonadotropins and estrogen in the postnatal ovary. Endocrinology 2004, 145:2433-2444.

34. Ahmad M, Srinivasula SM, Wang L, Talanian RV, Litwack G, Fernandes-Alnemri T, Alnemri ES: CRADD, a novel human apoptotic adaptor molecule for caspase-2, and FasL/tumor necrosis factor receptor-interacting protein RIP. Cancer Res 1997, 57:615-619.

35. Duan H, Dixit VM: RAIDD is a new 'death' adaptor molecule. Nature 1997, 385:86-89.

36. Miyahara N, Shoda J, Kawamoto T, Furukawa M, Ueda T, Todoroki T, Tanaka N, Matsuo K, Yamada Y, Kohno K, Irimura T: Expression of UDP-N-acetyl-alpha-D-galactosamine-polypeptide $\mathrm{N}$-acetylgalactosaminyltransferase isozyme 3 in the subserosal layer correlates with postsurgical survival of pathological tumor stage 2 carcinoma of the gallbladder. Clin Cancer Res 2004, 1 0:2090-2099.

37. Yamamoto S, Nakamori S, Tsujie M, Takahashi Y, Nagano H, Dono K, Umeshita K, Sakon M, Tomita Y, Hoshida Y, Aozasa K, Kohno K, Monden $\mathrm{M}$ : Expression of uridine diphosphate $\mathbf{N}$-acetyl-alphaD-galactosamine: polypeptide $\mathbf{N}$-acetylgalactosaminyl transferase 3 in adenocarcinoma of the pancreas. Pathobiology 2004, 7I:12-18.

38. Spadaro M, Ambrosino E, lezzi M, Di Carlo E, Sacchetti P, Curcio C, Amici A, Wei WZ, Musiani P, Lollini PL, Cavallo F, Forni G: Cure of mammary carcinomas in Her-2 transgenic mice through sequential stimulation of innate (neoadjuvant interleukin12) and adaptive (DNA vaccine electroporation) immunity. Clin Cancer Res 2005, I I:194|-1952.

39. Gentleman RC, Carey V], Bates DM, Bolstad B, Dettling M, Dudoit S, Ellis B, Gautier L, Ge Y, Gentry J, Hornik K, Hothorn T, Huber W, lacus S, Irizarry R, Leisch F, Li C, Maechler M, Rossini AJ, Sawitzki G, Smith C, Smyth G, Tierney L, Yang JY, Zhang J: Bioconductor: open software development for computational biology and bioinformatics. Genome Biol 2004, 5:R80.

40. Bolstad BM, Irizarry RA, Astrand M, Speed TP: A comparison of normalization methods for high density oligonucleotide array data based on variance and bias. Bioinformatics 2003, 19:185-193.

4I. Maglott D, Ostell J, Pruitt KD, Tatusova T: Entrez Gene: genecentered information at NCBI. Nucleic Acids Res 2005, 33(Database):D54-58.

42. Dudoit S, Gentleman RC, Quackenbush J: Open source software for the analysis of microarray data. Biotechniques 2003:45-5I.
Publish with Biomed Central and every scientist can read your work free of charge

"BioMed Central will be the most significant development for disseminating the results of biomedical research in our lifetime. "

Sir Paul Nurse, Cancer Research UK

Your research papers will be:

- available free of charge to the entire biomedical community

- peer reviewed and published immediately upon acceptance

- cited in PubMed and archived on PubMed Central

- yours - you keep the copyright 